\title{
BMJ Open Attitudes, access and anguish: a qualitative interview study of staff and patients' experiences of diabetic retinopathy screening
}

\author{
A E Hipwell, ${ }^{1}$ J Sturt, ${ }^{2}$ A Lindenmeyer, ${ }^{3}$ I Stratton, ${ }^{4}$ R Gadsby, ${ }^{5}$ P O'Hare, ${ }^{6}$ \\ P H Scanlon ${ }^{7}$
}

To cite: Hipwell AE, Sturt J, Lindenmeyer A, et al. Attitudes, access and anguish: a qualitative interview study of staff and patients' experiences of diabetic retinopathy screening. BMJ Open 2014;4: e005498. doi:10.1136/ bmjopen-2014-005498

- Prepublication history and additional material is available. To view please visit the journal (http://dx.doi.org/ 10.1136/bmjopen-2014005498).

Received 16 April 2014 Revised 20 August 2014 Accepted 21 August 2014

CrossMark

For numbered affiliations see end of article.

Correspondence to Professor J Sturt; jackie.sturt@kcl.ac.uk

\section{ABSTRACT}

Objective: To examine the experiences of patients, health professionals and screeners; their interactions with and understandings of diabetic retinopathy screening (DRS); and how these influence uptake.

Design: Purposive, qualitative design using multiperspectival, semistructured interviews and thematic analysis.

Setting: Three UK Screening Programme regions with different service-delivery modes, minority ethnic and deprivation levels across rural, urban and inner-city areas, in general practitioner practices and patients' homes.

Participants: 62 including 38 patients (22 regularscreening attenders, 16 non-regular attenders) and 24 professionals (15 primary care professionals and 9 screeners).

Results: Antecedents to attendance included knowledge about diabetic retinopathy and screening; antecedents to non-attendance included psychological, pragmatic and social factors. Confusion between photographs taken at routine eye tests and DRS photographs was identified. The differing regional invitation methods and screening locations were discussed, with convenience and transport safety being over-riding considerations for patients. Some patients mentioned significant pain and visual disturbance from mydriasis drops as a deterrent to attendance.

Conclusions: In this, the first study to consider multiperspectival experiential accounts, we identified that proactive coordination of care involving patients, primary care and screening programmes, prior to, during and after screening is required. Multiple factors, prior to, during and after screening, are involved in the attendance and non-attendance for DRS. Further research is needed to establish whether patient self-management educational interventions and the pharmacological reformulation of shorter acting mydriasis drops, may improve uptake of DRS. This might, in turn, reduce preventable vision loss and its associated costs to individuals and their families, and to health and social care providers, reducing current inequalities.

\section{Strengths and limitations of this study}

- Our purposive sampling strategy recruited several strata of professional groups in general practitioner and optometry practices and screening programmes, and in regular as well as lessregular attending patients. Additionally, we recruited from diverse city, town and rural locations, and included programmes with different regional invitation and delivery modes.

- Not every permutation between location type, deprivation and delivery-mode was studied. We did not recruit any practice that delivers screening in a mobile unit or hospital outpatients department so did not interview Hospital Eye Service staff, and only two practices provided optometrist screening.

- The qualitative findings from our purposive sample are not intended to be representative, but highlight important insights into barriers and enablers to screening attendance that will inform further research.

\section{INTRODUCTION}

Visual impairment is a significant worldwide health problem. ${ }^{1} \quad{ }^{2}$ Approximately 314 million people globally are visually impaired, with over $80 \%$ of this impairment being preventable or treatable. ${ }^{3}$ Diabetic retinopathy is a major cause of preventable vision loss in people with type 1 and type 2 diabetes in Europe, Africa, Asia and Australia ${ }^{4-13}$ and, until recently, ${ }^{14}$ has been the leading cause of preventable vision loss in European working-age populations. ${ }^{4} 10-12$ The proportion of vision loss caused by diabetic retinopathy is increasing globally. ${ }^{13}$ In addition to treatment costs, lost productivity and quality of life for patients with diabetic retinopathy contribute to personal and socioeconomic burdens. $^{15}$ 
Adequate diabetes control, regular screening and timely laser treatment can prevent visual impairment. ${ }^{1}{ }^{15}$ In England, routine diabetes care and diabetic retinopathy screening (DRS) are principally managed in primary care, while treatment for retinopathy takes place in secondary care. Issues surrounding diabetic retinopathy, therefore, have practice implications for medical and health professionals working in both settings. The UK Government's measurement of preventable vision loss from April 2013 recognises this top public health priority. The English NHS Diabetic Eye Screening Programme offers cost-effective annual screening to people with diabetes (types 1 and 2) over 12 years ${ }^{16}$ where $80 \%$ uptake is achieved. Screening uptake is assessed at the general practice level. Screening modes differ regionally, taking place either in general practitioner (GP) surgeries, hospitals or optometry practices (see figure 1). Screening typically takes 30 minutes. Patients' pupils are dilated with drops, affecting their vision for 4-6 h. Digital photographs are taken and the images examined by regional NHS retinal grading teams, who identify any pathology. Results are communicated to the patient and the GP. Patients with retinopathy requiring monitoring or treatment are referred to the Hospital Eye Service.

However, approximately $20 \%$ of people invited for DRS do not attend, ${ }^{17}$ with those from minority ethnic backgrounds and people living in deprived areas less likely to attend and more likely to have worse retinopathy. ${ }^{18-20}$ Inequalities in access to DRS in England ${ }^{i}$ have led to calls for further research, ${ }^{19}$ including qualitatively. ${ }^{21}$

Yet, deprivation alone does not explain all the uptake variability between GP practices and regions. For example, misunderstandings about the importance of diabetes and personal risk factors, and patients' lack of awareness, psychological factors or practical obstacles, can represent major barriers to attending screening. ${ }^{22}$ However, as attendance rates vary greatly between neighbouring practices, for example, from $55 \%$ to $95 \%$ in Gloucestershire, ${ }^{23}$ research focusing beyond deprivation, risk factors or barriers is required. Little is known about how patients' and professionals' perceptions and experiences of DRS may influence attendance. This paper, therefore, focuses on the experiences around DRS that may affect uptake from the accounts of people with diabetes and GP practice and screening staff.

\section{METHODS}

NRES Committee South West-Cornwall and Plymouth gave ethical permission $(10 / \mathrm{H} 0203 / 79)$ and all participants gave their informed consent. This work was supported by the National Institute of Health Research, Research for Patient Benefit grant PB-PG-1208-18043 and sponsored by Gloucestershire Hospitals NHS Foundation Trust.
Design of the research: This multiperspectival, ${ }^{24}$ crosssectional qualitative interview study used purposively sampled GP practices in four UK Primary Care Trusts across three regions, based on Indices of Multiple Deprivation, practice type, screening mode and screening uptake (see table 1).

Practice recruitment: Central England Primary Care Research Network and South West Diabetes Network provided research nurse assistance with GP practice recruitment.

Twelve GP practices were approached; two declined (existing research commitments); one withdrew prior to the start of participant recruitment (staff changes). Table 1 details the characteristics of nine participating GP practices. The Central Local Research Network paid service support costs of $£ 599.27$ to the participating GP practices.

\section{Participant recruitment}

Professionals: We purposively recruited 24 primary care and screening professionals with patient contact in differing roles around DRS, to ensure a broad spectrum of views and experiences. Patients. Within each practice, patients were purposively sampled based on their screening attendance history, to consider differences in attitudes and experiences. 'Regular attenders' had attended all three of their most recent DRS appointments; 'Non-regular attenders' had attended none or one of their three most recent DRS appointments. Practice staff telephoned potential participants and sent information packs.

Interviews: Semistructured interviews were conducted either face to face at the GP/optometry practice, in patients' homes, or by telephone, at participants' discretion. Multiperspectival interviews allowed us to understand the dynamics between patients, professionals and the Screening Programme, and to explore similarities and differences in their perceptions to highlight potentially differing needs and suggestions for improving services. Questions were aimed to capture the descriptions of participants' experiences before, during and after the screening appointment, from professionals' and patients' perspectives; identifying factors they believed influence screening attendance (see online supplementary appendices 1 and 2). All interviews were audiorecorded and transcribed verbatim, prior to analysis. No additional data are available for data-sharing.

Analysis: Data were managed using QSR NVivo10 software $^{\mathrm{ii}}$ to code and review themes. AEH undertook iterative, thematic analysis, using constant comparison within and across all transcripts. Looking for overarching themes and relations between them, AEH identified specific major and minor categories within the themes that might interact to influence screening attendance rates. AEH and AL met to discuss these themes and agreed on the definitions of the emerging

ihttp:/ / www.screening.nhs.uk/news.php?id=12156.

ii www.qsrinternational.com/. 
Figure 1 Diabetic eye screening programme delivery modes (GP, general practitioner).

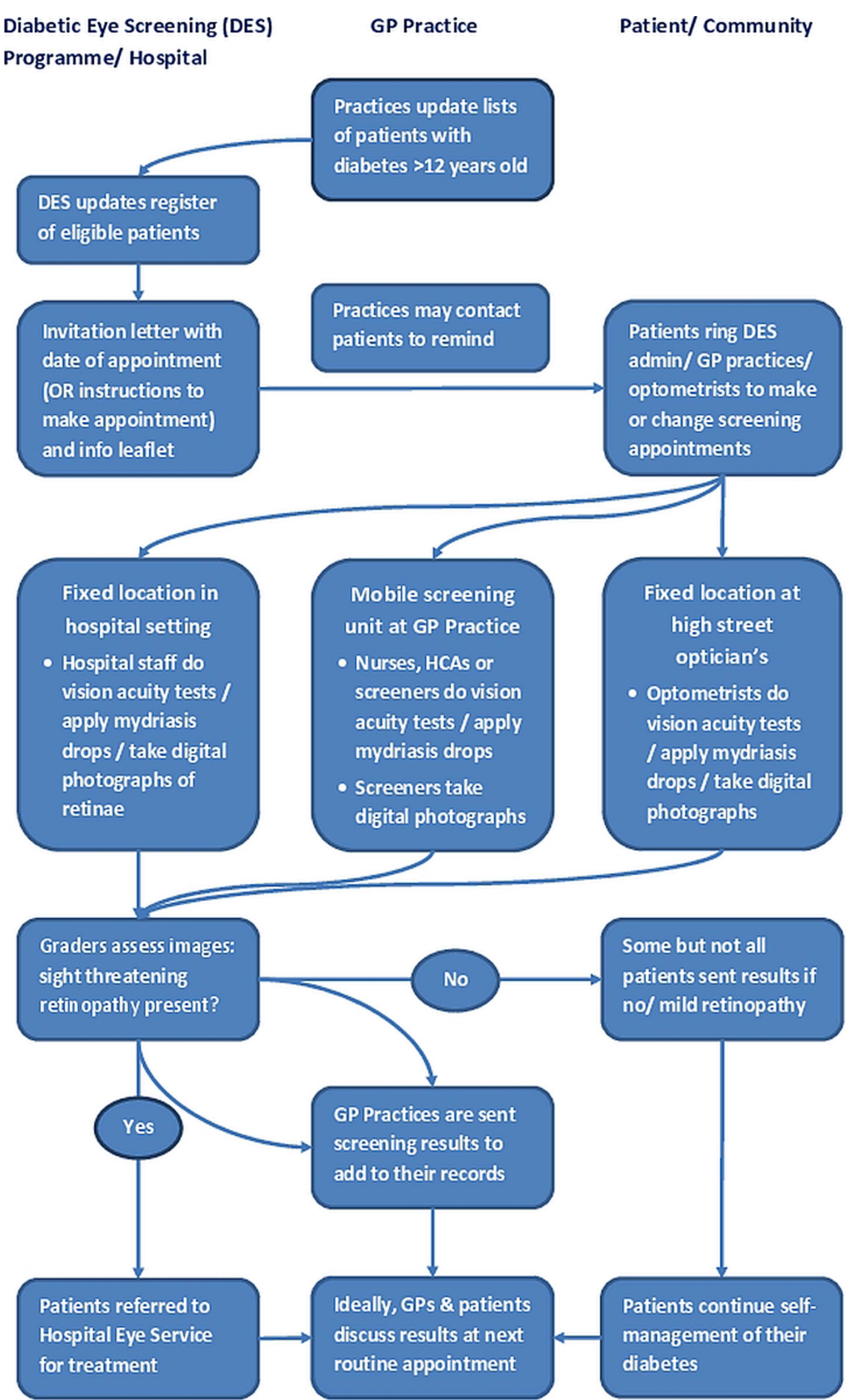

Table 1 Practice characteristics

\begin{tabular}{lllll}
\hline Practice number & $\begin{array}{l}\text { Screening } \\
\text { programme area }\end{array}$ & IMD & Practice type & $\begin{array}{l}\text { Screening } \\
\text { delivery mode }\end{array}$ \\
\hline Practice 1 & Region 1 & Deprived & Urban city & GP practice \\
Practice 2 & Region 1 & Below average & Rural town & GP practice \\
Practice 3 & Region 2 & Deprived & Rural town & GP practice \\
Practice 4 & Region 2 & Above average & Rural town & GP practice \\
Practice 5 & Region 1 & Deprived & Rural town & GP practice \\
Practice 6 & Region 1 & Below average & Urban city & GP practice \\
Practice 7 & Region 2 & Least deprived & Rural town & GP practice \\
Practice 8 & Region 3 & Most deprived & Inner city & High street optometrist \\
Practice 9 & Region 3 & Most deprived & Inner city & High street optometrist \\
\hline GP, general practitioner; IMP, index of multiple deprivation. & & & 75 \\
\hline
\end{tabular}


Table 2 Programme and participant characteristics

\begin{tabular}{|c|c|c|c|c|}
\hline $\begin{array}{l}\text { Screening programme } \\
\text { Regional descriptor }\end{array}$ & $\begin{array}{l}\text { Region } 1 \\
\text { Urban city/rural town }\end{array}$ & $\begin{array}{l}\text { Region } 2 \\
\text { Rural town }\end{array}$ & $\begin{array}{l}\text { Region } 3 \\
\text { Inner city }\end{array}$ & Total \\
\hline Number of practices & 4 & 3 & 2 & 9 \\
\hline Patients (non-regular attenders) & $14(5)$ & $8(1)$ & $16(10)$ & $38(16)$ \\
\hline Medical practice staff (GPs, optometrist, HCAs, nurses) & 2 & 3 & 3 & 8 \\
\hline Administrative practice staff (receptionists, managers) & 4 & 2 & 1 & 7 \\
\hline Screeners & 4 & 4 & 1 & 9 \\
\hline Total participants & 24 & 17 & 18 & 62 \\
\hline
\end{tabular}

codes. Findings were discussed with all authors until a consensus was reached about the interpretation of key themes. Finally, AEH checked these interpretations with the existing data.

\section{RESULTS}

Characteristics of the sample. Sixty-two participants (33 female) were interviewed between September 2011 and July 2012, by AEH, AL and JS (see table 2). Of the 38 patients, 4 have type 1 diabetes (mean age 49); 34 have type 2 (mean age 60); 22 were regular retinopathyscreening attenders, 16 were non-regular attenders (defined above). Of the 24 professionals (mean age 50), 8 are primary healthcare professionals, 7 are administrative practice staff and 9 are DRS programme screeners.

No theme was unique, either to the regular attenders or non-regular attenders, which highlights the complex nature of why people do or do not attend appointments.

\section{Understandings of diabetic retinopathy and screening}

The GP practice staff, screeners and patients identified several antecedents to attendance and non-attendance at screening. Regular and non-regular attending patient participants both acknowledged the importance of DRS. Yet, confusion around screening was clearly identified in all participant groups, as was the need to overcome this.

\section{Understandings of diabetic retinopathy}

Some (but not all-see later subthemes) people with diabetes understood the causal factors and the potential consequences of diabetic retinopathy; protecting their eyes appeared to be a priority for some. Interestingly, a non-regular attender with vicarious experience of sight loss identified herself to the researcher as a regular attender. Others found the process reassuring.

It's the smallest vessels that go first, and it's one of the quickest ways of seeing the effects is in the eyes. But...the body is so tolerant, you don't recognise that the vision is going until it's too late. Patient 8 (Region 2, Regular) ${ }^{\text {iii }}$

\footnotetext{
${ }^{\mathrm{iii}} \mathrm{R}=$ region from table 1 ; regular attender/non-regular attender (as defined above).
}

I: So what is it that encourages you to come [to screening] then?

P: My brother-in-law he was a very bad diabetic...He actually died from it. He went blind first. Patient 13 (Region 3 , Non-regular)

I like the fact that you instantly see and can get a decent steer on if there is anything negative; it's complete peace of mind - well my results anyway. Patient 3 (Region 2, Regular)

\section{Psychological, pragmatic and social influences on non-attendance}

In response to being asked why people might not attend DRS, professionals and patients both acknowledged that denial of having diabetes could contribute. One patient missed screening appointments because she disliked the proximity of the screener. Pragmatic reasons raised by the non-regular attenders for non-attendance included work commitments and postoperative recuperation.

Some people just... have their head in the... like the ostrich, they don't have diabetes or they're not taking any notice of it and they will just... yes, not come. Some because they think they can't have the time off work, you know? Screening Programme 1 (Region 1)

It's just the thought of somebody coming close to my eye. Patient 15 (Region 3, Non-regular)

I missed once, because I had an abscess in an awkward place, and I had to have an operation. But the following year I made sure. Patient 5 (Region 3, Non-regular)

Another non-regular attender who identified herself as a regular attender had attempted to access DRS via her GP practice, but was refused because she was in a temporary accommodation waiting to be rehoused. This highlights the complex social context in which people with diabetes experience screening:

Int: So you didn't always come?

Pt: Well, with being homeless for 8 weeks...But they [GP practice] didn't want to know. 'Oh you're not in our area.' I'm in nobody's area because we were in a bed and breakfast; they were my last doctors. Patient 10 (Region 1, Non-regular) 
Understandings of DRS versus routine eye test

Some patients' perceptions of screening attendance were confused by high street optometry practices routinely taking photographs during a general annual eye check. Patients confused this with DRS even in areas where high street optometry practices did not conduct DRS, confounding attendance:

I'm with [high street optometry chain] so I've always, always had my eyes screened...So when I was diagnosed and I told the optician she said, well we can do that here for an extra $£ 10$ and we will just email the surgery. So I thought fine, that's fine. So I just bypass it completely... Patient 4 (Region 2, Non-regular)

A lot of people turn up and say, 'well I had my optician's test' and you...explain to them that although it's a great thing to have and they need to have it, we still need to do our tests because it's more accurate, and we're searching specifically for the diabetic retinopathy. Screening Programme 1 (Region 1)

\section{Perceived responsibility for patients' understandings of DRS}

Professionals and patients identified the need to improve patients' understandings about DRS and sightthreatening retinopathy. For example, one GP accepted that low uptake reflected a failure to deliver the right message. However, more direct input from the health professional team was suggested by one patient who had not understood the screening information, and subsequently developed retinopathy. One screener considered that the lack of media attention to DRS could contribute to low attendance.

Why haven't they taken that onus of control, what is it that they don't believe about their diabetes? Where have we gone wrong in trying to get that message across?...the words "Diabetic Retinopathy Screening", what does that mean to them? Health Professional 1 (Region 3)

As soon as I had diabetes diagnosed somebody should have explained to me more fully what the implications are. Because it's alright them giving you a leaflet and sending you home...but even though you read it, there's this kind of silly thing, 'oh it won't happen to me', attitude. Patient 15 (Region 3, Non-regular)

I don't think screening is something that's pushed as much as other screening. I mean retinal screening is...I'd say it's important...but things like breast cancer, there's a lot more press about it. Screening Programme 2 (Region 1)

\section{Accessing DRS}

This theme highlights participants' varying experiences and perceptions around making the appointment, getting there-and back, which patients had difficulties with.

\section{Pre-booked versus self-booked appointments}

Invitation methods vary with regions (see figure 1), with professionals and patients identifying issues around both modalities that could affect uptake. Patients need to be proactive, either to make their appointment or change an inconvenient pre-booked appointment (depending on where they live). All participant groups identified that patients could forget to do either, while this appeared particularly problematic for working patients.

But it does rely on the patient being proactive. You get an appointment, alphabetical order, totally inconvenient, impractical time, what do you do, do you do nothing and forget it or do you ring up and change it? And if you don't ring up and change it then nothing happens, you're just a DNA statistic aren't you really. Screening Programme 3 (Region 1)

Int: So you get a letter with the appointment pre-booked?

Pt: Yes. And then if you can't make it you change it.

Int: You wouldn't prefer to be able to ring yourself and make an appointment?

Pt: No, because I think you'd tend to forget wouldn't you, and I think most people would. Patient 3 (Region 1, Regular)

Patients are used to receiving pre-booked appointments for other diabetes clinics (eg, Practice Nurse appointments to be weighed and have their feet checked). Professionals felt that expecting patients to make their own DRS appointment downgraded its perceived importance to patients, or was not patients' responsibility. This was exacerbated by the perceived rigidity of the appointment-booking system in another region.

I think if it's left to the patient a lot of the time they don't think, because they have to do it, it's not that important. Health Professional 4 (Region 3)

Why should a patient... if it was a blood test... would the GP just say, go and sort it out yourself, and the patient is just registering himself at the hospital, getting a blood test and making sure the GP gets it? That's ridiculous. Screening Programme 1 (Region 3)

I get a letter saying I need to make a phone call between specific times on specific dates and they give you a block of dates...to make the appointment in advance...a good 6 weeks. Patient 5 (Region 2, Regular)

Patients in the area delivering DRS through high street optometry reported an absence of available appointments:

Well before the appointment I phoned and they said no, they'd got no appointments for the next three months... The following year again the same thing, I phoned when I had the letter, they said three months' waiting. Patient 5 (Region 3, Non-regular) 


\section{Integrating diabetes appointments}

Patients in different regions suggested that DRS would be better if integrated with their other diabetes care as this would reduce the inconvenience of attending numerous appointments:

Probably would be better if it was done the same time as you have a normal diabetic appointment...I mean I've had to come up here on the Tuesday because they wanted to check my weight and then I think it was the Wednesday to have my eyes done and I'm thinking, do I need to come up twice [laughs]. Patient 8 (Region 1, Regular)

\section{Transport}

Getting to and from screening appointments was important pragmatically for many patients, who had to overcome a range of issues. One health professional recognised that transport issues and the proximity of screening to patients' homes potentially affected uptake, apparently understanding patients' reticence to travelalthough without the insight into the difficulties that some patients experienced:

\begin{abstract}
Most patients around here like to go to things that are within walking distance or within a bus stop, if that. So transport is an issue. ...they know the surgery, 'oh the surgery is next door, I know the girls there, they're always there'...So maybe I need to have the retinopathy screening done at the surgery and they'd all come [laughs]. Health Professional 1 (Region 3)
\end{abstract}

Patients are advised not to drive to/from DRS appointments, because the mydriasis drops cause blurred vision and photosensitivity (detailed later). The pragmatic repercussions of this were especially noteworthy for working age people. However, alternative travel arrangements also emerged as impractical because blurred vision caused an inability to navigate efficiently.

I am tied to either making them [screening appointments] in the afternoon and then getting home, so I have to work out how to get into work in the morning that doesn't involve driving, or I have to be there [GP practice] earlier, say lunch time or something, I have to take a half day. Patient 5 (Region 2, Regular)

Because of the drops, it makes it difficult for the people's journey...it's like a cobweb on top of your eyes and... No I can't see at all...We have to have the eye drops so it's very hard to either walk it back ...I felt I was blinded temporarily and got into a taxi and then got out of the car somehow. I had to cross the road and I was just looking like that [stares blankly] because I was waiting for the taxi and I had to do like that [waves arms]... Patient 5 (Region 3, Non-regular)

\section{Screening experiences}

This theme incorporates experiential accounts of the actual screening appointments of patients, including negative experiences of lengthy appointments in high street optometry practices, compared with efficient GP practice appointments. Mydriasis drops caused severe side-effects and subsequent adverse effects for some patients, who discussed strategies to overcome them.

\section{Appointment length}

In one region, appointments lasting for several hours at optometry practices were potentially a deterrent. One patient recognised that lengthy food abstinence was particularly inappropriate for diabetes patients, while another overcame the problem by changing practice.

Yes, the first time I went to...the local optician...I was there for 5 hours, from 10 o'clock in the morning, and by the time I got out of the door it was 3 o'clock....And by then I can remember I was so hungry and I thought, 'well how does that help a diabetic person?' Patient 5 (Region 3, Non-regular)

I had my optician before and he was quite slow, the drops used to sting and he used to take a long time. I had to be there for about two or three hours. But my present optician is good. Patient 1 (Region 3, Regular)

However, in sharp contrast, where screening was delivered in GP practices, satisfaction with short, efficient appointments had been reported.

They're quite good actually, see you straight away, well within, you know...about ten minutes of your appointment... Patient 8 (Region 1, Regular)

It doesn't take half an hour I suppose at the outside.

Patient 1 (Region 2, Regular)

\section{Side effects of drops}

Mydriasis drops dilate the pupil, allowing more light into the eye and a clearer retinal photograph to be taken. However, in another important finding, regular and non-regular patients experienced severe pain, blurred vision and debilitating photosensitivity for several hours. Interestingly, none of the health professionals except the optometrist raised this, suggesting they were unaware of this issue.

AEH: you come and they put the drops in do they?

P: Oh yes. They were like acid burning my eyes this time...It really hurt this time. Patient 1 (Region 1, Non-regular)

Everything else is fine, it's just the drops, they sting like hell. Patient 3 (Region 1, Regular)

And I hate that because it affects my eyes for so long and I can't... put my lenses back in straight away so someone is with me because I can't see... Patient 4 (Region 2, Non-regular)

I would advise anybody to bring sunglasses even if it's not particularly bright...if I had them I'd wear dark goggles 
so that they're closed in. Like welders goggles [laughs]. Actually no like swimming goggles but darker, to keep all the light out from the sides now, because it's painful. Patient 5 (Region 2, Regular)

If someone tomorrow has drops put in because of the service and they just happen to have a reaction to the drops, and they lose their eyesight...So then who are they going to sue? ... if push comes to shove we're the ones [optometrists] who are going to get sued. Screening Programme 1 (Region 3)

\section{DISCUSSION}

\section{Results in context}

For some patients and practices, the DRS programme worked well and we confirm previous findings that a convenient screening location near home was beneficial $^{24}$ and that preserving vision was prioritised among patients with diabetes. ${ }^{25}$ We also confirm previous studies finding that for others, misunderstandings about the importance of diabetes and personal risk, ${ }^{22}{ }^{26}$ lack of DRS awareness, psychological factors, practical obsta$\operatorname{cles}^{22}$ and the deterrent side effects of mydriasis ${ }^{27}$ represented potential attendance barriers.

No clear distinction between regular and non-regular DRS attenders was identified. In an important new finding, we uncovered confusion between routine retinal photography at optometry practices during eye examinations and DRS. While optometry photography may represent an important safeguard for non-attenders, it could impair more comprehensive coverage. We observed differences between patients screened at GP versus optometrist practices, identifying that ease of making an appointment, including its time, navigating home after the mydriasis drops, etc, appeared less problematic at GP practices. Furthermore, making patients responsible for arranging appointments in some regions, combined with encountering delays, could undermine the perceived importance of DRS. We have identified patients' misperceptions about their attendance regularity.

\section{Strengths and limitations of the study}

The strengths of this study include the purposive sampling strategy across several strata of professional groups in GP and optometry practices and screening programmes, and recruiting regular and less regular attending patients. Additionally, we recruited from diverse city, town and rural locations, and included programmes with different regional invitation and delivery modes. However, not every permutation between location type, deprivation and delivery mode was studied. We did not recruit any practice that delivers screening in a mobile unit or hospital outpatients department; so did not interview Hospital Eye Service staff, and only two practices provided optometrist screening. The qualitative findings from our purposive sample are not intended to be representative but to highlight sociocultural meanings of health and illness experiences, not simply their frequency, and identify important insights into barriers and enablers to screening attendance among our participants that will inform further research.

\section{Implications for clinicians and policy makers}

While some patients understood retinopathy and its causation, others lacked information and understanding about DRS. This calls for proactive personal clinical risk communication $^{28} \quad 29$ and attendance information to ensure care coordination between patients, primary care, screeners and screening programmes. The current guidance to bring sunglasses could be strengthened in the patient information. Some patients had confused retinal photography at optometry practices with DRS. Professional optometry bodies could ensure clarity among members, and optometrists should highlight the difference to their patients. Consideration may be appropriate around the responsibility that the NHS has when discharging visually impaired patients into the community. In Scotland, a 3-stage screening procedure is used; stage 1 is one field non-mydriatic photography, stage 2 is dilation, stage 3 is slit-lamp biomicroscopy on those with poor quality mydriatic images who required dilation in stage 2. The Scottish Screening Programme dilate approximately $34 \%$ of their population. The English Screening Programme developed following the evidence provided for 2-field digital photography by the Scanlon et $a l^{30}$ study, which recommended dilated two-field imaging. Culturally sensitive improvements ${ }^{21}$ should build on the recent introduction of patient information leaflets in several languages. ${ }^{\text {iv }}$

Several providers now deliver DRS in the UK, and since this research was conducted, Public Health England is responsible for overseeing delivery and the financial incentive for GPs to record screening uptake has been removed. These changes may affect future practice involvement and patient uptake; this fast-moving field requires monitoring closely. Building on the successful central appointments system and practice factors that affect DRS attendance ${ }^{31}$ may prove useful. The national implementation of the new screening pathway should ensure consistent delivery throughout the country, improving the quality of services and reducing variability. ${ }^{32}$

\section{Future research}

Much more work is needed is this field. A similar exercise should be undertaken among a representative national sample of programmes, taking into account demographic variables that we found to be relevant (ethnicity, delivery mode, deprivation etc). More work is needed to determine the prevalence of the views of patients and clinicians on the appropriate design and delivery of DRS services to maximise attendance; hospital staff may provide insightful alternatives for service

\footnotetext{
${ }^{\text {iv }}$ http:/ / diabeticeye.screening.nhs.uk/languages.
} 
improvement. The pharmacological reformulation of shorter acting mydriasis drops to minimise side effects may reduce disruption to patients and potentially benefit uptake rates, although we acknowledge that this would not address the pain participants had reported. The extent of confusion about optometry photography needs urgent assessment.

\section{CONCLUSIONS}

This study uses the experiences of the DRS staff and patients to start unpicking factors affecting uptake. The factors identified include differing regional invitation methods and screening locations, convenience, transport safety and short appointment times; some patients experienced significant side effects from mydriasis drops. The successful implementation of the new care pathway should address these factors, which may improve DRS attendance. Used as an international model, this could, in turn, contribute to reducing preventable vision loss and inequalities globally, and its associated costs to individuals and their families, as well as to primary, secondary and social care providers.

\section{Author affiliations}

${ }^{1}$ CLAHRC-WM, Warwick Business School, University of Warwick,

Coventry, UK

${ }^{2}$ Florence Nightingale School of Nursing and Midwifery, King's College

London, London, UK

${ }^{3}$ Department of Primary Care Clinical Sciences, School of Health and Population Sciences, University of Birmingham, Edgbaston, Birmingham, UK ${ }^{4}$ Gloucester Diabetic Retinopathy Research Group, Cheltenham General Hospital, Gloucester, UK

${ }^{5}$ Warwick Medical School Education \& Development, University of Warwick, Coventry, UK

${ }^{6}$ Division of Metabolic \& Vascular Health, Warwick Medical School, University of Warwick, Coventry, UK

${ }^{7}$ Diabetic Retinopathy Screening Programme (England), Gloucestershire Eye Unit and Oxford Eye Hospital, Cheltenham General Hospital, Gloucester, UK

Acknowledgements The authors thank the GP and optometry practices and screening programme staff who took part in the study, and the patients who gave their time and shared their experiences and thoughts. They acknowledge the input and guidance of patient representative Mr Mike Whatmore on the Steering Group. The authors thank members of Warwick Diabetes Research Education Group for their constructive feedback on patient materials and early protocols. Kay Webb collected some data.

Contributors IS had the original idea, and made substantial contributions to the conception of the work; PHS led the funding application. JS and AL made substantial contributions to the qualitative component of the study. All authors contributed to the early design of the work. AEH, the project manager, obtained ethical approval, and conducted the interviews with $A L$ and JS. AEH led the qualitative analysis and interpretation of data, and drafted the paper. All authors contributed to writing and revising the paper critically for important intellectual content and approved the final version of the paper. PHS is guarantor. All authors agree to be accountable for all aspects of the work in ensuring that questions related to the accuracy or integrity of any part of the work are appropriately investigated and resolved.

Funding This work was supported by the National Institute of Health Research, Research for Patient Benefit grant reference: PB-PG-1208-18043 and sponsored by Gloucestershire Hospitals NHS Foundation Trust. The Central Local Research Network paid Service Support Costs of $£ 599.27$ to participating GP practices.
Competing interests PHS is the director of the NHS Diabetic Eye Screening Programme; AEH has personal experience of mydriasis drops.

Patient consent Obtained.

Ethics approval NRES Committee South West-Cornwall and Plymouth: 10/H0203/79.

Provenance and peer review Not commissioned; externally peer reviewed.

Data sharing statement Copies of the participant information sheet can be obtained by emailing the corresponding author-a.e.hipwell@warwick.ac.uk

Open Access This is an Open Access article distributed in accordance with the Creative Commons Attribution Non Commercial (CC BY-NC 4.0) license, which permits others to distribute, remix, adapt, build upon this work noncommercially, and license their derivative works on different terms, provided the original work is properly cited and the use is non-commercial. See: http:// creativecommons.org/licenses/by-nc/4.0/

\section{REFERENCES}

1. WHO. Priorities and objectives — what do we want to achieve? 3.5.8 Diabetic retinopathy. Chapter in VISION 2020: The Right to Sight? 2004.

2. World Health Organization, ed. Prevention of blindness and visual impairment (WHA59.25). Geneva, 2006.

3. Resnikoff S, Pascolini D, Etya'ale D, et al. Global data on visual impairment in the year 2002. Bull World Health Organ 2004:82:844-51.

4. Scanlon P. The English national screening programme for sight-threatening diabeticretinopathy. J Med Screen 2008:15:1-4

5. Raman R, Rani P, Reddi Rachepalle S, et al. Prevalence of diabetic retinopathy in India: Sankara Nethralaya Diabetic Retinopathy Epidemiology and Molecular Genetics Study report 2. Ophthalmology 2009;116:311-18.

6. Seyoum B, Mengistu Z, Berhanu P, et al. Retinopathy in patients of Tikur Anbessa Hospital diabetic clinic. Ethiop Med J 2001;39:123-31.

7. Tapp R, Shaw J, Harper C, et al. The prevalence of and factors associated with diabetic retinopathy in the Australian population. Diabetes Care 2003;26:1731-7.

8. Knudsen L, Lervang H, Lundbye-Christensen S, et al. The North Jutland County Diabetic Retinopathy Study: population characteristics. Br J Ophthalmol 2006;90:1404-9.

9. Wang $F$, Liang $Y$, Zhang $F$, et al. Prevalence of diabetic retinopathy in rural China: the Handan Eye Study. Ophthalmology 2009;116:461-7.

10. Scanlon P. Diabetic retinopathy screening-progress or lack of progress. In: Tombran-Tink J, Barnstable C, Gardner T, eds. Visual dysfunction in diabetes: the science of patient impairment and improvement. Springer, 2012:17-30.

11. Kocur I, Resnikoff $S$. Visual impairment and blindness in Europe and their prevention. Br J Ophthalmol 2002;86:716-22.

12. Hesse L, Grusser M, Hoffstadt K, et al. Population-based study of diabetic retinopathy in Wolfsburg. Ophthalmologe 2001;98:1065-8.

13. Bourne R, Stevens GA, White RA, et al. Causes of vision loss worldwide, 1990-2010: a systematic analysis. Lancet Glob Health 2013;1:e339-49. http://www.thelancet.com/journals/langlo/article/ PIIS2214-109X(13)70113-X/fulltext.

14. Liew G, Michaelides M, Bunce C. A comparison of the causes of blindness certifications in England and Wales in working age adults (16-64 years), 1999-2000 with 2009-2010. BMJ Open 2014;4: e004015.

15. Viswanath K, McGavin DD. Diabetic retinopathy: clinical findings and management. Community Eye Health 2003;16:21-4.

16. Waqar S, Bullen G, Chant S, et al. Cost implications, deprivation and geodemographic segmentation analysis of non-attenders (DNA) in an established diabetic retinopathy screening programme. Diabetes Metab Syndr 2012;6:199-202. http://www.sciencedirect.com/ science/article/pii/S1871402112001129

17. England PH. NHS Diabetic Eye Screening Programme, Statistics. 2013 (23 September 2013). http://diabeticeye.screening.nhs.uk/ statistics

18. Gulliford MC, Dodhia $\mathrm{H}$, Chamley $\mathrm{M}$, et al. Socio-economic and ethnic inequalities in diabetes retinal screening. Diabet Med 2010;27:282-8

19. Johnson M, Cross V, Scase M, et al. A review of evidence to evaluate effectiveness of intervention strategies to address inequalities in eye health care: a report to RNIB. De Montfort University, 2011 RNIB/CEP/01. 
20. Sivaprasad S, Gupta B, Gulliford M, et al. Ethnic variations in the prevalence of diabetic retinopathy in people with diabetes attending screening in the United Kingdom (DRIVE UK). PLOS ONE 2012;7: e32182. http://www.plosone.org/article/info\%3Adoi\%2F10.1371\% 2Fjournal.pone.0032182

21. Kliner M, Fell M, Gibbons C, et al. Diabetic retinopathy equity profile in a multi-ethnic, deprived population in Northern England. Eye 2012;26:671-722.

22. Eborall H, Davies R, Kinmonth A-L, et al. Patients' experiences of screening for type 2 diabetes: prospective qualitative study embedded in the ADDITION (Cambridge) randomised controlled trial. BMJ 2007;335:490.

23. Scanlon $\mathrm{P}$, Carter S, Foy C, et al. Diabetic retinopathy and socioeconomic deprivation in Gloucestershire. J Med Screen 2008:15:118-21.

24. Kendall M, Murray S, Carduff E, et al. Use of multiperspective qualitative interviews to understand patients' and carers' beliefs, experiences, and needs. BMJ 2009;339:b4122.

25. van Eijk K, Bloma J, Gusseklooa J, et al. Diabetic retinopathy screening in patients with diabetes mellitus in primary care: incentives and barriers to screening attendance. Diabetes Res Clin Pract 2012;96:10-16.
26. Lewis $\mathrm{K}$, Patel D, Yorston D, et al. A qualitative study in the United Kingdom of factors influencing attendance by patients with diabetes at ophthalmic outpatient clinics. Ophthalmic Epidemiol 2007;14:375-80.

27. Murgatroyd H, MacEwen C, Leese GP. Patients' attitudes towards mydriasis for diabetic eye disease screening. Scott Med J 2006;51:35-7.

28. Stratton I, Adler A, Aldington S, et al. A simple algorithm to estimate the time to development of sight-threatening diabetic retinopathy. Lancet 2012;380(S3):S69.

29. Stratton I, Aldington S, Taylor J, et al. A simple risk stratification for time to development of sight-threatening diabetic retinopathy. Diabetes Care 2013;36:580-5.

30. Scanlon PH, Malhotra R, Thomas G, et al. The effectiveness of screening for diabetic retinopathy by digital imaging photography and technician ophthalmoscopy. Diabet Med 2003;20:467-74.

31. Lindenmeyer A, Sturt J, Hipwell A, et al. How do primary care practices influence their patients' uptake of diabetic retinopathy screening? A qualitative case study. Br J Gen Pract 2014;64:e484-92.

32. NHS Diabetic Eye Screening Programme Newsletter. Working together to roll out new pathway. 2013. 